No. 3(60), 2019, pp. 103-113

https://doi.org/10.12797/Politeja.16.2019.60.07

\author{
María José BRUÑA BRAGADO D \\ Universidad de Salamanca \\ mjbruna@usal.es
}

\title{
NUEVAS CARTOGRAFÍAS DEL HUMANISMO A PARTIR DE LA ESCRITURA
}

\section{RESISTENCIAS LITERARIAS CHILENAS: \\ NONA FERNÁNDEZ Y ALIA TRABUCCO}

ABSTRACT New Writing's Cartographies of Humanism. Chilean Literary Resistances: Nona Fernández and Alia Trabucco

Testimonial and Fiction Writings of recent past, especially traumatic recent past, have effects and impacts in our complex contemporary times. This confusing, disenchanted, liquid present is the mark of neoliberalism and biopolitics in bodies and minds ("threaten eros", Byung Chul-Han said). However, we can find an answer to death, pain and ideological scepticism and individualism in a community of affection (Berardi, Emmelhainz), in the pleasure of language, in humor or lightness (Todorov Calvino). The way to access knowledge is diverse and social and poetic memories can be more interesting than historical documents. The trauma of Chilean postdictatorship is written and told by contemporary narrative in a mixture of fantastic and realistic engagement. These writers are part of the postmemory generation (Hirsch). Mapocho (2002) by Nona Fernández and La resta by Alia Trabucco are the books who can help us to draw a possible map of some Chilean literary resistance.

Key words: biopolitics, resistance, postmemory, gender, Chile 
El drama está en que el progreso se ha convertido en finalidad de la humanidad, y no la humanidad en la finalidad del progreso

Joan-Carles Mèlich

Es más importante entender que recordar pero para entender primero hay que recordar

Susan Sontag

Los regímenes totalitarios del siglo XX han revelado la existencia de un peligro antes insospechado: la supresión de la memoria

Tzvetan Todorov

$\mathrm{E}^{\mathrm{l}}$ l espíritu de este encuentro se sitúa a las antípodas del pensamiento descreído del filósofo alemán Peter Sloterdijk quien plantea en Normas para el parque humano que tras las atroces coyunturas bélicas que han jalonado siglo XIX y XX con sus devastadoras consecuencias socieconómicas; tras exterminios, dictaduras militares y flujos de refugiados cada vez más desamparados por la comunidad internacional, después de la implantación hegemónica del sistema capitalista que sigue al fracaso del comunismo y sus consecuencias sobre las vidas y los cuerpos - como lúcidamente advertía el periodista argentino Rodolfo Walsh en su "Carta abierta de un escritor a la Junta Militar"1 en la que subrayaba que la peor herencia de las dictaduras del Cono Sur era la violencia económica, la miseria "planificada" que asedia los centros de grandes urbes como Buenos Aires o Santiago de Chile - tras todo esto, como decía, el humanismo, los neohumanismos están - según Sloterdijk - obsoletos como corriente para abordar y pensar de forma crítica el mundo globalizado y postcapitalista, la sociedad de la modernidad tardía. No es tiempo ya, arguye en su polémica con Habermas, de confiar en el ser humano y, acercándose a los postulados de la "banalidad del mal" de Hannah Arendt y recuperando la imagen del "ángel de la historia” de Walter Benjamin que pone su ojo apocalíptico en el pasado y el futuro, se aleja del conocimiento o la educación como formas de mejorarnos, como "acontecimientos éticos"2. Sin embargo, George Steiner, Primo Levi, Tzvetan Todorov, Didi-Huberman, Lévinas, Jorge Semprún, Reyes Mate o Joan-Carles Mèlich consideran que hay ciertos restos de humanidad incluso en las

1 "Estos hechos, que sacuden la conciencia del mundo civilizado, no son sin embargo los que mayores sufrimientos han traído al pueblo argentino ni las peores violaciones de los derechos humanos en que ustedes incurren. En la política económica de ese gobierno debe buscarse no sólo la explicación de sus crímenes sino una atrocidad mayor que castiga a millones de seres humanos con la miseria planificada. [...] Basta andar unas horas por el Gran Buenos Aires para comprobar la rapidez con que semejante política la convirtió en una villa miseria de diez millones de habitantes". R. Walsh, "Carta abierta de un escritor a la Junta Militar”, en H. Verbitsky, Rodolfo Walsh y la prensa clandestina, 1976-1978, Buenos Aires 1985, p. 121.

2 J.C. Mèlich, Totalitarismo y fecundidad. La filosofía frente a Auschwitz, Barcelona 1998. 
circunstancias más terribles que se resisten a ser obliterados, que el mal puede ser "domesticado" aunque nunca eliminado, pues es siempre susceptible de repetirse. La idea de que en los campos de concentración (nazis, soviéticos y, en nuestro caso particular, en los chilenos, argentinos de los 70) se podía encontrar una fraternidad extrema, una empatía, un cuidado de la alteridad de la misma manera que se puede encontrar cierta comprensión o cierta paz con el pasado reciente violento en la generación de los hijos y nietos - denominada también "generación de la posmemoria" por Marianne Hirschilumina el trabajo que presento a continuación.

\section{BIOPOLÍTICA}

En su Tesis sobre la filosofía de la historia Walter Benjamin declara que nuestro concepto de historia debe asentarse sobre una idea difícil de digerir pero clave: vivimos en un perpetuo estado de excepción. Décadas más tarde, Michel Foucault, en una formulación que le debe mucho a Benjamin, da forma a una noción que se revelaría fundamental para pensar el escalofriante siglo XX - tan violento como los anteriores y los posteriores, diría Arendt, pues la violencia es intrínseca al ser y la sociedad, y aparece allí donde el poder se tambalea - y que sería desarrollada ampliamente por Giorgio Agamben y Peter Sloterdijk: la "biopolítica" que supondría la gestión política absoluta, la intervención o intrusión calculada del poder-saber en todas las facetas de la vida humana. En El poder soberano y la nuda vida, primer tomo de su trilogía Homo sacer (1995), Giorgio Agamben afirma, de hecho, que el paradigma de la extensión global en la aplicación extrema de la "biopolítica" es el campo de concentración. Así, el testimonio de Levi (1947) o el de Semprún (1963), referidos a los campos del nazismo y, más recientemente, los de Hernán Valdés (1974) o Pilar Calveiro (1998), concernientes a los campos de concentración chilenos o argentinos, son espléndidos ejercicios de recuperación del trauma a través de la escritura que dialogarían entre sí, más allá del momento histórico preciso, más allá de las identidades nacionales, desde ambos lados del Atlántico.

En la catarsis que supone el acto perlocutivo subjetivo, sea en forma de ficción, sea en forma testimonial, se incluyen, entonces, modalidades, líneas de fuga o miradas a esa experiencia del pasado sanadoras y revulsivas, resistentes al biopoder, que parten del hecho que señalaba Lévinas de que no vivimos en singular, de que somos algo más que cuerpos desnudos, dóciles. Todorov señala en Frente al límite tres tipos de virtudes presentes en la vida cotidiana de los campos y en las experiencias límite tanto en las vividas directamente como de forma diferida - por los hijos expatriados de los torturados y desaparecidos: dignidad, cuidado y estética o actividades del espiritu. Creo que ese aferrarse a la subjetividad, a la fraternidad y a la imaginación o lo estético de cuerpos vueltos transparentes por el mal es frecuente en las crónicas de ficción de la represión escritas desde una mirada con distancia temporal ("posmemoria") y trasatlántica. Las tres fueron formas de resistencia y supervivencia plasmadas en estrategias discursivas comunes durante la dictadura militar chilena y vamos a constatar su presencia en las crónicas ficcionales de los protagonistas indirectos del horror, como en el caso de Nona Fernández o Alia 
Trabucco, desde una revisión del concepto teórico de la posmemoria (Hirsch) - al margen de que con frecuencia los textos postmemorialísticos se hayan convertido en productos de consumo que responden a las demandas de un mercado ávido de memorias del pasado reciente ${ }^{3}$. Mi revisión conceptual desvelará la legitimidad de esta propuesta que trata de conceder, además, un lugar en la memoria histórica social a la memoria histórica femenina o subalterna y de relacionar la responsabilidad individual y social hacia ese pasado persistente al que se refiere Marianne Hirsch ${ }^{4}$. Se trata, en última instancia, como afirma Pilar Calveiro, de una decisión consciente de no olvidar, como demanda ética y como resistencia a los relatos cómodos. En este sentido, la memoria es sobre todo acto, ejercicio, práctica colectiva, que se conecta casi invariablemente con la escrituras.

\section{CHILE. LA "REVOLUCIÓN CAPITALISTA"}

Los certeros análisis de Benjamin acerca de la vida moderna, el discurso y la experiencia - y el progresivo empobrecimiento, pérdida o deterioro de esta última por ese avance tecnológico que implica el progreso y tras eventos traumáticos como la guerra - abren este apartado que pretende explorar el estado de shock o mudez puntual del pueblo chileno, la incapacidad inicial para transmitir la experiencia del horror por parte de sus intelectuales, periodistas, artistas, aturdidos ante el radical cambio de paradigma que supuso el golpe de Estado a Salvador Allende en $1973^{6}$. Las estrategias del poder neoliberal, de ese "biopoder" que mantiene su plena vigencia en los 70 en el Cono Sur, se hicieron más sofisticadas y extremas, al amparo de las demoledoras teorías económicas de la Escuela de Chicago, y se implementaron rápidamente en Chile, como explica con lucidez Naomi Klein en su ensayo La doctrina del Shock. El auge del capitalismo del desastre. La crítica canadiense traza, en este libro, la genealogía del capitalismo y afirma que el momento fundacional de la "dictadura de los mercados" de nuestro presente globalizado no fue sino el 11 de septiembre de 1973, coyuntura en la que el shock de la población fue tal que posibilitó la aplicación vertiginosa de un programa de reformas neoliberales (clasistas, brutales), que no se podía haber llevado a cabo en momento democrático alguno - pese a que, y volviendo a Benjamin, toda democracia sea una suerte de "estado de excepción" más o menos velado. Se trataba de que "el acontecimiento" - visto por

3 Luis Martín-Cabrera sostiene que para evitar que la memoria sea solamente un producto de consumo de mercado y para luchar contra las políticas de olvido implementadas por el Estado, es preciso dejar de considerar la memoria en términos abstractos. Sólo así, los lectores y espectadores podrán adquirir una conciencia crítica sobre las implicaciones éticas de esta temática.

4 Se pueden trabajar estas mismas nociones en las novelas de Martín Kohan: Dos veces junio (2002) y Ciencias morales (2007) o en Una misma noche de Leopoldo Brizuela (Premio Alfaguara, 2012), en Formas de volver a casa (2011) de Alejandro Zambra o Una vez Argentina de Andrés Neuman (2004).

5 P. Calveiro, Poder y desaparición: los campos de concentración en Argentina, Buenos Aires 2004, p. 377

6 Jorge Semprún explicaría en diversas ocasiones la necesidad de escoger, en el momento inmediatamente posterior al "peligro", entre vivir o recordar el trauma. Solo si se escoge la vida, y no la escritura (o verbalización de una experiencia inédita, completamente nueva), es posible aunar fuerzas para hacer, posteriormente, la catarsis. J. Semprún, La escritura o la vida, trad. T. Kauf, Barcelona 1997. 
Pinochet como una "guerra" contra el marxismo, enemigo interior - fuera lo más rápido, dramático y traumático posible.

Así, Chile fue el primer, y "exitoso", ejemplo de la estrategia o terapia del shock social. El país del Cono Sur - más tarde también Argentina, Uruguay y Brasil, aunque con menor "fortuna" - fue una suerte de laboratorio en el uso del aturdimiento incrédulo y de la conmoción para imponer el libre mercado y la doctrina neoliberal. Difícilmente el shock podía haber sido mayor porque, como recuerda Klein, a diferencia de la vecina Argentina, que habia sido dirigida por seis gobiernos militares en los cuarenta años previos, Chile carecia de experiencia en este tipo de violencia: habia disfrutado de 160 años de pacífico gobierno democrático, los últimos 41 años ininterrumpidos ${ }^{8}$.

Cualquier forma de resistencia u oposición se convirtió en mortal a partir de septiembre del 73 en un Chile en el que la tortura y el terror se diseminaron a través de sus innumerables campos de concentración: más de 3.200 personas fueron ejecutadas o desaparecieron, 80.000 fueron encarceladas y 20.000 huyeron del pais por motivos politicos 9 . De este modo, se transformaron, en pocos años y por completo, las relaciones sociales y las políticas económicas en lo que constituyó una forma más duradera de violencia a través de la creación de enormes desigualdades y una miseria creciente. En suma, tenemos constancia de que Chile nada tuvo que ver con los fascismos clásicos sino con una nueva manera de capitalismo radical cuya condición de existencia fue el terrorismo de estado y cuyos excesos se separaban, cuidadosamente, de los dominios ético y político. Chile, protagonista de lo que Tomás Moulian denomina "revolución capitalista"10, fue modelo, experimento y siniestro laboratorio de ese control "biopolítico" absoluto fundado en un terror y brutalidad necesarios ${ }^{11}$. Esta violencia "moderna" y organizada condiciona vidas, decisiones y también, por supuesto, el lenguaje con el que se dice el mundo en una situación límite.

\section{HISTORIAS, RÉPLICAS, RESISTENCIAS Y "POSMEMORIA"}

La imposición de una verdad unívoca o una versión histórica oficial, hegemónica, genera réplicas, resistencias. Otras versiones, según la "metahistoria" (Michel Riffaterre, Hayden White) circulan, se afianzan y hacen fuertes como elementos contestatarios

\footnotetext{
"En Chile, Pinochet tuvo las manos libres para destripar a la clase media gracias a la forma devastadora y aterradora en que se hizo con el poder". N. Klein, La doctrina del shock. El auge del capitalismo del desastre, trad. I. Fuentes García, Barcelona 2007, p. 126.

8 Ibid., p. 110.

9 Ibid., p. 111.

10 T. Moulian, Chile actual. Anatomía de un mito, Santiago de Chile 1997.

11 "Hacia 1988, cuando la economía se había estabilizado y crecido con rapidez, el 45\% de la población había caído por debajo del umbral de la pobreza. El 10\% más rico de los chilenos, sin embargo, había visto crecer sus ingresos en un $83 \%$. Incluso en 2007 Chile seguía siendo una de las sociedades menos igualitarias del mundo. De las 123 naciones en que Naciones Unidas monitoriza la desigualdad, Chile ocupaba el puesto 116, lo que le convierte en el octavo país con más desigualdades de la lista”. Ibid, p. 122.
} 
que introducen matices, nuevos factores y variables desde la estética, sea arte plástico, cine, literatura. $Y$ es que a veces se simula una acción que nunca ocurrió y en ocasiones moldea lo que sí ocurrió pero apuntando más a la belleza que a la verdad (Anderson Imbert). Al conocimiento histórico se accede de muchas maneras y no sólo - ya sabemos a través de los documentos rigurosamente oficiales, políticos, jurídicos, sino también y sobre todo - desde las memorias sociales y poéticas.

El trauma del Chile dictatorial y postdictatorial es relatado con lucidez por su narrativa contemporánea desde ópticas que entremezclan el hiperrealismo con lo fantástico y renuevan la noción de compromiso o militancia (Jacques Rancière), de "suerte ética" y "muerte fraterna" 12 . Se trata de escritores pertenecientes a lo que Marianne Hirsh ha designado como "generación de la posmemoria" o "generación de los hijos", primero aplicado a las víctimas del Holocausto y después, en sentido amplio a las víctimas del trauma y los que comparten espacio con los hijos de los que fueron víctimas en primera persona - como en el caso argentino Patricio Pron, Laura Alcoba o, en el chileno, Alejandro Zambra. Dominick LaCapra, por su parte, define posmemoria como "la memoria adquirida de experiencias que no se han vivido en carne propia"13.

Mapocho (2002) de Nona Fernández y La resta (2015) de Alia Trabucco nos servirán de guía para articular un posible mapa de resistencias literarias en Chile que van más allá del testimonio.

Hay dos preguntas que se cruzan y me interpelan en la narración de la violencia reciente y las políticas de la memoria, no sólo en Chile sino en los países del Cono Sur, y tienen que ver con esas dos modalidades estéticas y discursivas señaladas antes: el hiperrealismo y lo fantástico. El hiperrealismo a secas lo representarían novelas como las de Alejandro Zambra, Martín Kohan, Selva Almada o Ariana Harwicz. Lo fantástico, en su vertiente más grotesca, Mariana Enríquez o Nona Fernández. Esta segunda línea está relacionada con la emergencia de voces subalternas - zombis, niños muertos, fantasmas y elementos distópicos vinculados con la ciencia-ficción como en Chicos que vuelven frente a una narrativa descarnada, brutal, cruda que se explaya en el exceso y lo abyecto - mugre, etc..., estética que lleva a los límites el realismo sucio por su fuerte contenido político - se trata de dotar al desecho, al fragmento, al resto, de sentido político y hacer una crítica a la opresión económica, que es también política. Parece que se apunta a un duelo permanente, en suspenso, a un estado entre la vida y la muerte, a un purgatorio perpetuo.

El segundo cruce que planteo tiene que ver con la experimentación vs la literatura tradicional a la hora de contar el pasado reciente con lo cual ya tenemos cuatro variables y una combinatoria narrativa amplia - fantástico, hiperreal, experimental, tradicional. Damián Tabarovsky en su controvertido ensayo Literatura de izquierda ${ }^{14}$ habla de que la literatura realmente interesante, que aporta algo es la que arriesga y va más allá y en su opinión, el realismo exacerbado, la mímesis reproduce estructuras conservadoras,

12 J. Semprún, La escritura...

13 D. LaCapra, Escribir la historia, escribir el trauma, trad. E. Marengo, Buenos Aires 2005, p. 124.

14 D. Tabarovsky, Literatura de izquierda, Cáceres 2010. 
refleja el estado de cosas y expresa, veladamente, un conformismo ideológico, social, político, refleja el orden burgués, capitalista, postcapitalista. En realidad, para vivir de otra manera hay que hablar o decir de otra manera. Todo pasa por transformar el decir. Repetir la forma con otros contenidos no es político o, como afirmaba Paul Éluard, hay otros mundos pero están en este. Y es que, Platón dixit, cuando el modo de la música cambia, los muros de la ciudad tiemblan. Cuestionamos, no obstante, la hipótesis del argentino, como veremos a continuación.

En Mapocho (2003), Nona Fernández subvierte la historia de Chile desde la conquista y lo hace desde la intromisión de lo fantástico para denunciar abusos y excesos con la llegada de los españoles, pero también durante la dictadura y la posdictadura a través de una economía generadora de una brecha social obvia. Fernández realiza un giro en su estética de la misma manera que lo hace Diamela Eltit que pasa de atacar lo político a desenmascarar el neoliberalismo y el control o vigilancia panóptica que implica en sus últimos textos, donde la violencia se inscribe y encarna, desde una perspectiva biopolítica, sobre los cuerpos. La incursión en lo fantástico de Nona Fernández se combina en este caso con un lenguaje hasta cierto punto mimético, se enmarca en una narratividad no experimental, sin rupturas semánticas o conceptuales que no apuntan a la construcción de una distopía, sino que es llevada a cabo a través de ciertas distorsiones puntuales donde lo grotesco, lo abyecto emergen como residuos soñados, crípticos trasladados en un lenguaje realista, mimético. Así, su narrativa se vale de la tradición - especialmente de la oral - y de una mimesis interrumpida para reescribir la historia y completarla. Por ejemplo, en Mapocho Fausto es un intelectual designado por el régimen militar para escribir la historia oficial de Chile, lo que lo convierte en un traidor hasta para su familia a la que abandona porque se le promete gloria y seguridad económica. Se situaría este personaje en la "zona gris" de Primo Levi pues tendría una complicidad con el establishment debido a su silencio - de una forma similar a Urrutia-Lacroix, el protagonista de Nocturno de Chile de Roberto Bolaño. En Mapocho hay otro gran protagonista: el río, operador espacial, topológico que tuvo mucha significación, como sabemos, en el Chile de Pinochet. Por otra parte, aparecen otros tres personajes "subalternos" a los que, como querría Spivak, hay que dotar de voz: La Rucia, el Indio y la madre. Todos hablan desde la muerte que un accidente de tráfico les ha provocado en su desesperada huida al Mediterráneo. Sus cuerpos heridos, magullados, doloridos hablan por ellos de la violencia del accidente fortuito, azaroso, pero también de todas las violencias nada azarosas y de dos secretos difíciles de guardar: el incesto - eros como salvación, lo que se plantea también en la novela La resta - y la mentira sobre la que se construye la relación materno-filial la madre les dice a sus dos hijos, la Rucia y el Indio, que su padre murió en un incendio. Lo interesante en esta obra, y cito a Lucía Guerra es que "la muerte no se concibe como una extinción final, por el contrario, ella es una modalidad de la vida de la cual, por su constante transformación, mantiene ad infinitum, el ciclo vital que sostiene al universo inmortalmente perdurable". El estatuto de "muertos" les permite ver lo que los vivos no ven y aunque son almas en pena suspendidas en un duelo permanente, en un suspense melancólico, tienen más lucidez para mirar el mundo y la sociedad postdictatorial. La memoria del horror procede, pues, de los cuerpos muertos, de los cuerpos que hablan de 
sus "pequeños dolores", pero también de la versión de la historia oficial de Fausto - salpicada de oralidad - y en tercer lugar del río Mapocho. Es un río cargado de memoria. El agua, frente a la vida, es aquí muerte por los cadáveres que viajan en él. Es una cicatriz del pasado reciente de la ciudad. El río Mapocho es una gran fosa común. La pregunta por el pasado reciente - personal, colectivo - atraviesa toda la novela fantasmáticamente. Cito: El pasado tiene la clave. Es un libro abierto con todas las respuestas. Basta mirarlo, revisar sus páginas y abrir los ojos con cuidado para caer en cuenta. El pasado es un lastre del que no hay cómo librarse. Es mejor adoptarlo, darle un nombre, aguacharlo bien aguachado bajo el brazo, porque de lo contrario pena como un ánima con los rostros más inesperados. Tortura con la forma de un olor, de una música, a veces de un sueño. Un sueño siempre es un reflejo de algo que ocurrió (Mapocho 173).

Así, la mirada de víctimas de la segunda o tercera generación - la novela resulta ser un largo flash back de la Rucia y el Indio - junto al recurso a la oralidad y el folklore a través de proverbios, sermones, canciones, marcas que habitan el texto, constituye la canción trágica del Mapocho, el intento de decir, verbalizar o, al menos balbucear e intuir, ese pasado desde la fraternidad.

Entre vida y muerte, concreción y abstracción, presente y pasado, realidad y fantasía se mira la historia melancólicamente: ni el exilio fue una solución para los hermanos ni el insilio para su padre, devastado física y moralmente en el Santiago neoliberal. $\mathrm{He}$ aquí, entonces, el primer ejemplo de narrativa no experimental en el lenguaje pero con guiños fantásticos que rozan con frecuencia, y tal vez paradójicamente, el hiperrealismo, para decir el horror y resistir en la letra y la memoria.

En La resta (2015) de Alia Trabucco se hace también un ejercicio de memoria y mirada al pasado - hay un mandato materno de "no olvidar" - a partir del encuentro de tres hijos de las víctimas de la dictadura de Pinochet y la búsqueda - delirante, al estilo de una siniestra "road movie" en un coche funerario - del cuerpo sin vida de una de las madres, Ingrid Aguirre, muerta en el exilio y, contra todo pronóstico, de cáncer. La mirada es doble o triple, pero se encarna en dos narradores, dos de los hijos: Iquela, con un discurso más ordenado y racional, y Felipe, cuyo discurso es desestructurado, obsesivo, neurótico porque no ha curado el duelo a tiempo y no deja de contar compulsivamente muertos en su particular aritmética del dolor, en su intento de entender, racionalizar la herida. Recordemos con Hannah Arendt que la normalización de la violencia impide identificar a los sujetos y hacer el duelo - “ ¿cómo ajustar las matemáticas mortales y los listados?". El contraste entre la mirada de los militantes, de los padres miembros de la Resistencia chilena - unos exiliados; otros en insilio permanente como la madre de Iquela que vive instalada en la paranoia y los terceros muertos por delación o traición precisamente el padre de su compañero Felipe - es obvio. El río Mapocho vuelve a ser clave en esta novela; es - y cito - una línea en la palma de la mano, el cauce de la sangre. Otra vez vuelve la noción de herida pero también de vida pues los personajes están enraizados a esta urbe (atrapados; nunca se van).

El triángulo Iquela-Paloma-Felipe está atravesado por pulsiones eróticas transgresoras, aunque aquí no haya incesto - "llévame contigo" le dice Iquela a Paloma para escapar a través del eros al horror del recuerdo - que no parecen ofrecer la solución al trauma, 
como sucediera ya en Mapocho. "Esperar. Mirar. Saber" son verbos que vertebran toda la novela y apuntan hacia la necesidad de una "poética de la memoria", una vez transcurrido el tiempo pertinente. La pregunta es "¿qué se hace con los muertos-vivos?, ¿̇e suman o se restan?". Se habla constantemente de cadáveres sin vida porque también existen los cadáveres con vida, los muertos-vivos, atrapados - como Consuelo, la madre de Iquela y como los desaparecidos en ese estatus fantasmático, ese limbo. Es imposible "reparar" desde lo jurídico, como se afirma en varios momentos de la novela: "compensaciones, expiaciones, decía Felipe entre risas", pero la afectividad, la amistad de los tres, la idea de comunidad - como proponen el teórico Franco Berardi o Irmgard Emmelhainz - como apuntaban también antes Lévinas, Semprún, Levi o Todorov, puede ser una forma de resistencia y ayudar a construir una memoria alternativa, una memoria poética. Sorprende que en La resta lo fantástico irrumpa con fuerza solo al final, en el último capítulo cuando todo lo demás está escrito en clave realista - aunque con pasajes de nebulosa onírica también provocados por las drogas que consumen los protagonistas y están muy bien reflejados en el lenguaje. Para llegar a cero en su cuenta, Felipe, narrador, nos cuenta su metamorfosis en ave que sobrevuela Santiago; en ave fénix, ave fabulosa, mítica que perece quemándose pero vuelve a renacer de sus propias cenizas. Lo fantástico se yuxtapone al realismo más exacerbado y crudo; la experimentación de la mano de la tradición y la mímesis sirven, pues, en la narrativa chilena contemporánea para contar con lucidez y extraordinario dominio lingüístico, alegórico, el pasado reciente. Por otra parte, dignidad, cuidado y estética, o subjetividad, fraternidad e imaginación, las tres virtudes cotidianas de Todorov están presentes en estas novelas y apuntan a nuevas modalidades de resistencia humanista, de confianza en el potencial del arte, la literatura y los seres humanos para sobreponerse al trauma, al dolor. Recordar, entender, mejorar.

En definitiva, se opta por otra forma de compromiso - personal, crítico, problematizador y siempre desde la autonomía intelectual - que se concreta en un desenmascaramiento a través de la parodia y el hibridismo de géneros, a través de una implacable alegoría constituida a partir de pasajes, elementos y personajes simbólicos. Se insiste en ambas novelas en la necesidad de la memoria, en el deber ético de la memoria, así como en el delicado papel de la víctima-testigo de la historia y los hijos, no víctimas, no testigos en coyunturas delicadas y en lo universal e imposible de erradicar - no de domesticar - el binomio establecido entre el mal y la belleza. Se constata de este modo esa construcción, fallida desde su propia concepción, de la civilización o modernidad sobre el horror y la barbarie y se nos hacen repensar las lógicas con la que se sigue articulando la historia, las relaciones implícitas entre humanismo y violencia. Solo desde ahí es posible reactivar cierto compromiso ético.

\section{CODA: LA PARADOJA DEL “ÁNGELUS NOVUS”}

Terminemos recordando, nuevamente, la imagen que rescata Benjamin del cuadro de Paul Klee "Ángelus Novus" en su tesis IX: ese ángel aterrado, con los ojos clavados en el pasado - que no es una serie o cadena sino un solo, descomunal, devastador 
acontecimiento catastrófico, pero que no puede menos de seguir mirando hacia el futuro, de mirar hacia un progreso construido sobre esa catástrofe. Los textos de Fernández y Trabucco muestran la importancia de esa mirada al pasado, de ese ejercicio memorialístico para que la construcción del futuro, para que ese progreso vertiginoso que nos arrastra sin remedio sea lo más autoconsciente, lo más ético y reflexivo posible, pues, como defiende Bataille, la esencia de la moral no es sino la interrogación sobre la propia moral. Como recuerda siempre Reyes Mate citando a Kafka, sólo hay un futuro si la nueva generación tiene las patas traseras bien asentadas en el pasado.

\section{BIBLIOGRAFÍA}

Agamben G., Lo que queda de Auschwitz. El archivo y el testigo. Homo Sacer III, trad. A. Gimeno Cuspinera, Valencia 2000.

Alcántara Sáez M., Ruiz Rodríguez L. (eds.), Chile. Política y modernización democrática, Barcelona 2006.

Arendt H., Sobre la violencia, trad. G. Solana, Madrid 2003.

Benjamin W., "Experiencia y pobreza", en idem, Obras, libro 2, vol. 1, eds. R. Tiedemann, H. Schweppenhäuser, trad. J. Navarro Pérez, Madrid 1989.

Benjamin W., Tesis sobre la historia y otros fragmentos, trad. B. Echeverría, México 2005.

Calveiro P., Poder y desaparición: los campos de concentración en Argentina, Buenos Aires 2004.

Certeau M. de, La escritura de la historia, trad. J. López Moctezuma, México 1984.

Debord G., La société du spectacle, Paris 1992.

Didi-Huberman G., Supervivencia de las luciérnagas, trad. J. Calatrava, Madrid 2009.

Foucault M., Historia de la sexualidad. 1. La voluntad del saber, México 1975.

Foucault M., Vigilar y castigar. Nacimiento de la prisión, Madrid 1998.

Jelin E., Los trabajos de la memoria, Buenos Aires 2002.

Klein N., La doctrina del shock. El auge del capitalismo del desastre, trad. I. Fuentes García, Barcelona 2007.

LaCapra D., Escribir la historia, escribir el trauma, trad. E. Marengo, Buenos Aires 2005.

Lazzara M.J., Los años de silencio. Conversaciones con narradores chilenos que escribieron bajo dictadura, Santiago de Chile 2002.

Mèlich J.C., Totalitarismo y fecundidad. La filosofia frente a Auschwitz, Barcelona 1998.

Moulian T., Chile actual. Anatomia de un mito, Santiago de Chile 1997.

Peris Blanes J., La imposible voz. Memoria y representación de los campos de concentración en Chile. La posición del testigo, Santiago de Chile 2005.

Reyes Mate M., "Memoria de la barbarie y construccion del futuro", Nuestra Memoria (Museo del Holocausto), vol. 17, no. 36 (2012).

Richard N., Residuos y metáforas. Ensayos de crítica cultural sobre el Chile de la Transición, Santiago de Chile 1998.

Semprún J., La escritura o la vida, trad. T. Kauf, Barcelona 1997.

Steiner G., Presencias reales ¿Hay algo “en” lo que decimos?, trad. J.G. López Guix, Barcelona 1992. 
Sloterdijk P., Normas para el parque humano. Una respuesta a la 'Carta sobre el humanismo' de Heidegger, trad. T. Rocha Barco, Madrid 2006.

Tabarovsky D., Literatura de izquierda, Cáceres 2010.

Valdés H., Tejas verdes. Diario de un campo de concentración en Chile, Santiago de Chile 1996.

Walsh R., "Carta abierta de un escritor a la Junta Militar", en H. Verbitsky, Rodolfo Walsh y la prensa clandestina, 1976-1978, Buenos Aires 1985.

Wittgenstein L., Tractatus lógico-philosophicus, Madrid 1987.

María José BRUÑA BRAGADO - Full Professor in the Area of Latinamerican Literature in University of Salamanca and member of Instituto de Iberoamericana. She is interested in Gender and Postcolonial Studies and Cono Sur Contemporary Poetry and Narrative. She has published critical essays as Delmira Agustini. Dandismo, género y reescritura del imaginario modernista (Peter Lang, 2005) and Cómo leer a Delmira Agustini: algunas claves criticas (Verbum, 2008) or the anthology of Uruguayan poetry: Austero desorden. Voces de la poesia uruguaya reciente (Verbum, 2011). She has edited Todo de pronto es nada (Ediciones Universidad de Salamanca, 2015), critical anthology of Ida Vitale's work, XXIV Premio Reina Sofía de Poesía Iberoamericana. She has also coordinated Vértigo y desvelo: Dimensiones de la creación de Ida Vitale (Biblioteca de América, Universidad de Salamanca, 2017). 